\title{
High Performance Liquid Chromatography (HPLC) Analysis, Antioxidant, Antiaggregation of Mangosteen Peel Extract (Garcinia mangostana L.)
}

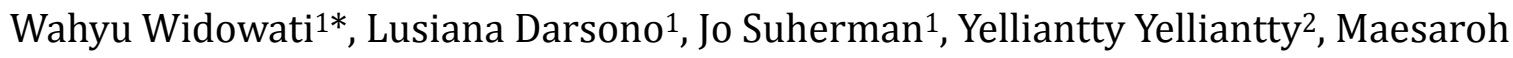 \\ Maesaroh $^{2}$ \\ ${ }^{1}$ Medical Research Center, Faculty of Medicine, Maranatha Christian University, Jl. Prof. Drg. Surya Sumantri \\ 65, Bandung 40164, West Java, Indonesia. \\ 2Biomolecular and Biomedical Research Center, Aretha Medika Utama, Jl. Babakan Jeruk 2 no 9, Bandung, \\ 40163, West Java, Indonesia.
}

*Corresponding author. Tel.: +62222012186; email: wahyu_w60@yahoo.com

Manuscript submitted March 7, 2014; accepted July 16, 2014.

doi: 10.17706/ijbbb.2014.4.6.458-466

\begin{abstract}
Atherosclerosis as one of the causes of cardiovascular disease will induce endothelial dysfunction and platelet aggregation. Mangostin peel extract (MPE) contains xanthones which have antioxidant activity, anti-cholesterol, anti-aggregation, and anti-inflammatory in preventing and inhibiting atherosclerosis. In this research, MPE was evaluated the xanthones quantitative based on standard xanthone compounds using High Liquid Performance Chromatography (HPLC) method and tested anti-aggregation platelet activity and ABTS+ 2,2-Azinobis-(3 ethylbenzothiazoline-6-sulfonic acid) diammonium (ABTS)-reducing activity. The anti-aggregation platelet using agonist namely adenosine diphosphate inducer (ADP), collagen (COLL), and epinephrine (EPN). Quantification of MPE using four xanthones compound as a marker, showed that MPE contained $\alpha$-mangostin 105 ppm, $\gamma$-mangostin 7.20 ppm, 9.92 ppm Gar-C, and Gar-D 3.50 ppm. MPE and xathones had high ABTS-reducing activity and the most active was, $\alpha$-mangostin with $\boldsymbol{I}_{\mathbf{5 0}} 2.348 \mu \mathrm{g} / \mathrm{ml}$. $\alpha$ mangostin and $\gamma$-mangostin had anti-aggregation activity on EPN inducer were comparable with aspirin. MPE and xathones had no anti-aggregation activity on COLL and ADP inducer. MPE contain xathones including $\alpha$-mangostin, $\gamma$-mangostin, Garcinone-C and Garcinone-D. MPE and xanthones have high ABTSreducing activity. MPE, $\alpha$-mangostin, $\gamma$-mangostin, Garcinone-D decrease EPN-induced aggregation platelet. $\alpha$-mangostin, $\gamma$-mangostin were the most active antia-ggregation and antioxidant activities.
\end{abstract}

Key words: Mangostin, xanthone, aggregation platelet, atherosclerosis, cardiovascular disease.

\section{Introduction}

Cardiovascular disease (CVD) is a non-communicable disease that causes the most deaths in the world in 2030 and it is estimated as many as 23.6 million people will die by CVD, especially coronary heart disease and stroke. The largest increase in mortality is expected to occur in Southeast Asia [1]. Atherosclerosis, one of the CVD trigger, is a complex and multifactorial process involving genetic and environmental factors [2], [3]. Platelet aggregation plays an important role in thrombus formation due to uncontrolled blood clots. Formed thrombus can lead to blockage of the coronary arteries and blood vessels in the brain. Plateletdependent thrombus formation is a key event in the pathogenesis of acute myocardial infarction (AMI) [4], 
[5]. Platelet tests is necessary for predicting cardiovascular disease clinical outcomes and to monitor antiaggregation drugs [6]. The use of platelet anti-aggregation in long-term has a recurrent arterial thrombotic, the failure of aspirin to prevent an arterial thrombotic or aspirin resistance [6], patients who are resistant to aspirin are at a greater risk of clinically important cardiovascular morbidity [7], it is necessary to search natural ingredients that have anti-aggregation activity with minimal side effects and more safe. One of the natural ingredients that has anti-aggregation platelet activity is polyphenol compounds that can prevent the formation of atherosclerosis, endothelial damage, leukocyte activation, adhesion, aggregation and secretion of platelets [8], [9].

Mangostin peel contains polyphenols which xanthone possessing antioxidant, antitumoral, antiallergic, anti-inflammatory, antibacterial, antifungal and antiviral properties [10]-[12].

The current knowledge indicates that MPE have several bioactivities but anti-aggregation property has not been reported yet. Therefore, we conducted our research to assay based on standard xanthones including $\alpha$-mangostin, $\gamma$-mangostin, garcinone-C (Gar-C), garcinone-D (Gar-D) by using HPLC method and platelet anti-aggregation of mangostin peel extract and xanthones by in vitro test.

\section{Material and Method}

\subsection{Plant Materials and Extract Preparation}

G. mangostana was collected from Cisalak-Subang, west Java, Indonesia. The plants were identified by staff of herbarium of the Department of Biology, School of Life Sciences and Technology, Bandung Institute of Technology, Bandung, West Java, Indonesia. The peels were colleted, chopped and kept in drier tunnel device and extracted throught maceration method with ethanol $70 \%$ as solvent. The dried of mangosteen peel (350 g) were ground and immersed in ethanol. After $24 \mathrm{~h}$, the filtrate was collected, this treatment was repeated until the filtrate remained colorless, the filtrate was evaporated with a rotary evaporator at $40^{\circ} \mathrm{C}$ for getting MPE [13],[14].

\subsection{Quantitative Analysis of High Performance Liquid Chromatography (HPLC) Profiling}

The analysis of chemical profiling of MPE by HPLC. Quantification MPE using the standard xanthones included $\alpha$-mangostin, $\gamma$-mangostin, Gar-C, Gar-D. Analysis using the Shimadzu HPLC Reverse Phase Column C-18 (Kinetex 2.6um; $150 \mathrm{~mm} \times 4.6 \mathrm{~mm}$ ID) and Shimadzu SPD-10A UV detector. The mobile phase was acetonytril $70 \%$ and delivered isocratically with a flow rate of $1.0 \mathrm{ml} / \mathrm{min}$. The samples were dissolved in methanol $70 \%$ as solvent $(1 \mathrm{mg} / \mathrm{ml})$ and filtered through a $0.22 \mu \mathrm{m}$ syringe and injected $20 \mu \mathrm{l}$. UV absorbance was measured at $244 \mathrm{~nm}$. This study did not use statistical analysis and quantification performed of duplicate measurement [15], [16].

\subsection{ABTS-Reducing Activity}

The antioxidant capacity MPE and xanthones were measured by using the ABTS+ 2, 2-Azinobis-(3 ethylbenzothiazoline-6-sulfonic acid) diammonium salt free radical assay [17]-[19]. This method 2,2Azinobis-(3 ethylbenzothiazoline-6-sulfonic acid) was produced by reacting $14 \mathrm{mM}$ ABTS and equal volume of $4.9 \mathrm{mM}$ potassium persulfate achieved final concentration $7 \mathrm{mM}$ ABTS in $2.45 \mathrm{mM}$ potassium persulfate). The mixture was incubated in the dark room temperature for $16 \mathrm{~h}$. The ABTS ${ }^{+}$solution was diluted with $5.5 \mathrm{mM}$ PBS (pH 7.4) and measured with microplate reader at $745 \mathrm{~nm}$ resulted absorbance of $0.70 \pm 0.02$. Briefly $2 \mu \mathrm{l}$ sample was added to $198 \mu \mathrm{l}$ of $\mathrm{ABTS}^{+}$solution, incubated for $6 \mathrm{~min}$ and the absorbance was measured at $30^{\circ} \mathrm{C}, 745 \mathrm{~nm}$. The percentage inhibition in ABTS radical of each sample was expressed by the ratio of the lowering of the absorption of ABTS+ $(\%)$, relative to the absorption (100\%) of $\mathrm{ABTS}^{+}$solution in the absence of test sample (negative control). ABTS-reducing activity (\%) was calculated 
in following formula and continued calculating as median Inhibitory Concentration $\left(\boldsymbol{I C}_{\mathbf{5 0}}\right)$ [17]-[19].

$$
I=\left(A_{\mathrm{c}}-A_{\mathrm{s}}\right) / A_{\mathrm{c}} \times 100
$$

where, $I=\% \mathrm{ABTS}^{+}$inhibition; $A_{\mathrm{c}}=$ negative control absorbance (without sample); $A_{\mathrm{s}}=$ sample absorbance

\subsection{Anti-aggregation Platelet Activity}

MPE and xanthones ( $\alpha$-mangostin, $\gamma$-mangostin, Gar-C, Gar-D) and aspirin as positive control were diluted in dimethyl sulfoxide (DMSO 1\%) achieving at level 1000 and $500 \mu \mathrm{g} / \mathrm{ml}$. Agonist using EPN, COLL and ADP were diluted in buffer saline ( $\mathrm{NaCl} 0.9 \%$ ) achieving the concentration $300 \mu \mathrm{M}, 10 \mu \mathrm{g} / \mathrm{ml}$ and 20 $\mu \mathrm{M}$ respectively. Blood was colletected from hyperaggregation individual with informed consent using the guidelines approved by the Institutional Ethics Committee collaboration between Maranatha Christian University, Bandung, Indonesia and Immanuel Hospital Bandung, Bandung, Indonesia. Briefly $9 \mathrm{ml}$ blood was collected and added with $1 \mathrm{ml} 3.8 \%$ sodium citrate as anticoagulant. The blood was centrifuged at 100× $\mathrm{g}$ for 10 min to obtain the platelet rich plasma (PRP). The PRP was maintained at room temperature for 30 min. Platelet poor plasma (PPP) was prepared by recentrifuging the remaining blood samples at $1600 \times \mathrm{g}$ for $10 \mathrm{~min}$. PPP was then removed, placed in a plastic tube, and the tube was maintained at room temperature [20], [21]. Briefly $200 \mu \mathrm{l}$ of PPRP was pippeted into a cuvette added $25 \mu \mathrm{l}$ the anti-aggregation agents (MPE, $\alpha$-mangostin, $\gamma$-mangostin, Gar-C, Gar-D, aspirin) and $25 \mu \mathrm{l}$ agonist (EPN, COLL, ADP). Pipette $250 \mu \mathrm{l}$ PPP into a cuvette as a blank. This blank will be used to set the 100\% aggregation. Aggregation activity was measured by Platelet Aggregation Chromogenic Kinetic System (PACKS-4) [21]-[23].

\subsection{Statistical Analysis}

The antiaggregation activities were replicated three times. The data was calculated for the values of means and standard deviation $(\mathrm{M} \pm \mathrm{SD})$ and $95 \%$ confidence interval $(\mathrm{CI})$ of means. To compare among treatments, the data was analysed by using the analysis of variance (ANOVA) with one-factorial completely randomized design. To know the difference of means among treatments and the best treatment, we used Tukey HSD Post-Hoc test 95\% confidence interval. Statistical analysis used SPSS 20.0 program.
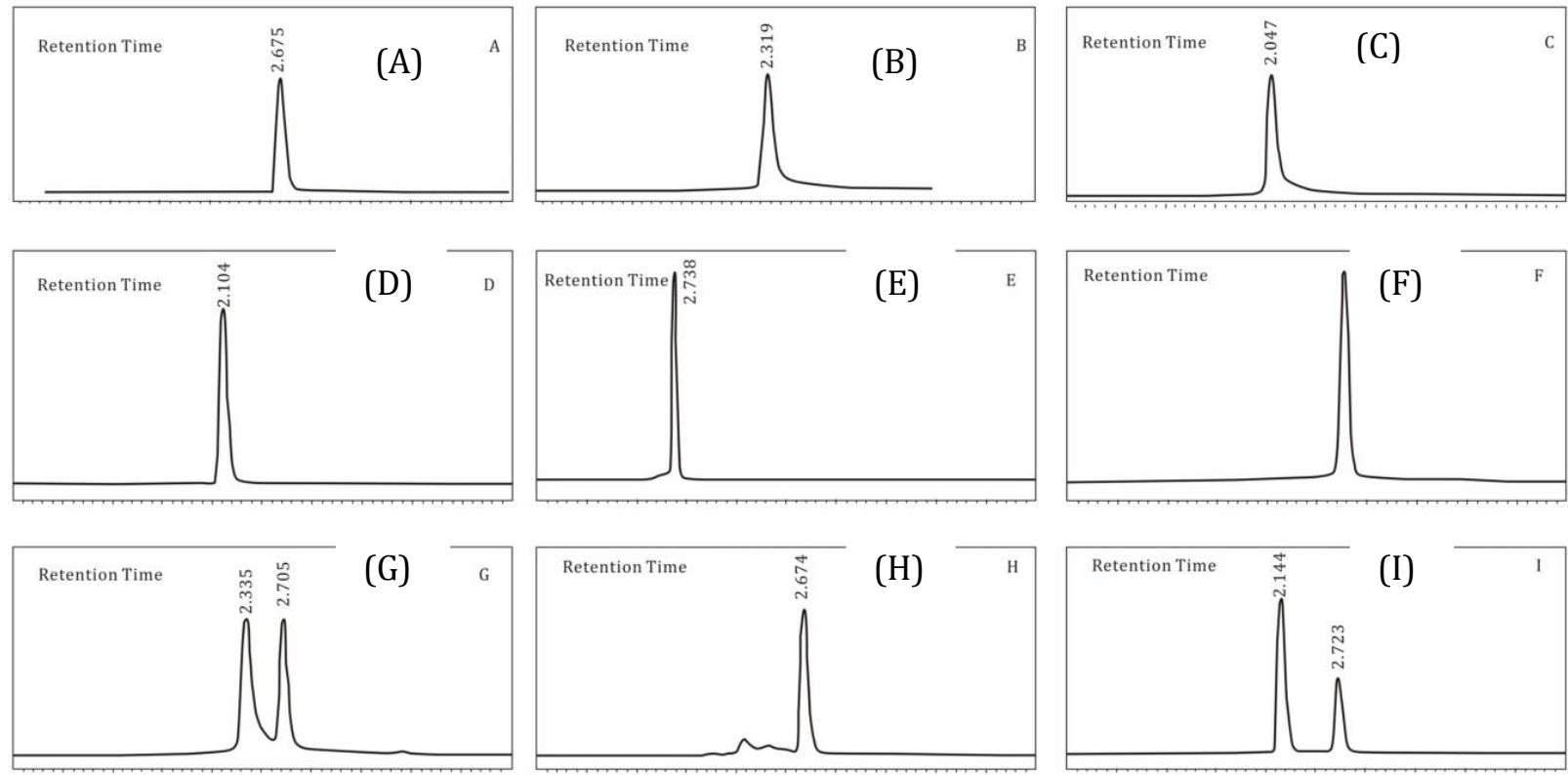

Fig. 1. HPLC spectrum of the MP using Methanol as solvent at $244 \mathrm{~nm}$ absorbance. (A) chromatgram of $\alpha$ mangostin; (B) $\gamma$-mangostin, (C) garcinone-C; (D) garcinone-D; (E) chromatogram MPE-1; (F) chromatogram MPE-2; (G) chromatogram MPE $+\gamma$ mangostin; (H) MPE+ garcinone-C; (I) MPE+garcinone-D. 


\section{Results and Discussion}

\subsection{HPLC Profiling of MPE}

Methanol $70 \%$ as solvent ( $1 \mathrm{mg} / \mathrm{ml}$ ) of MPE, $\alpha$-mangostin, $\gamma$-mangostin, Gar-C, Gar-D. The plant extract, compounds was filtered through a $0.22 \mu \mathrm{m}$ syringe filter prior to analysis. Spectra were generated on a Shimadzu SCL-10A (Japan). The separation was carried out at $25^{\circ} \mathrm{C}$ on a reverse phase C-18 column (Kinetex 2.6um; $150 \mathrm{~mm} \times 4.6 \mathrm{~mm}$ ID) and Shimadzu SPD-10A UV detector. The mobile phase was acetonytril $70 \%$ and delivered isocratically with a flow rate of $1.0 \mathrm{ml} / \mathrm{min}$. The sample volume injected was $20 \mathrm{ul}, \mathrm{MPE}$ and xathones were eluted at $244 \mathrm{~nm}$ at the retention time (tR) of 2.73 and 2.77 min. $\alpha$ mangostin showed characteristic peaks of MPE at the same retention time as that of standard, indicating MPE contained $\alpha$-mangostin in high level, but low concentration for $\gamma$-mangostin, Gar-C, Gar-D (Fig. 1) and the detail area, retention and xanthones content in the MPE can be seen at Table 1.

Table 1. Xanthones Concentration in MPE Based on HPLC

\begin{tabular}{lcccccc}
\hline Marker & Equation & \multicolumn{2}{c}{ Area (replication) } & Concentration (replication) & $\begin{array}{c}\text { Average } \\
\text { Concentration } \\
\text { (ppm) }\end{array}$ \\
\cline { 3 - 7 } & & 1 & 2 & 1 & 2 & 111,10 \\
\hline$\alpha$-mangostin & 62683 & 6964062 & 6199785 & 98,91 & 7,20 \\
$\gamma$-mangostin & 35937 & 194017 & 323461 & 5,40 & 9,00 & 3,50 \\
Gar-C & 47416 & 163365 & 169159 & 3,45 & 3,57 & 9,92 \\
Gar-D & 13410 & 134600 & 131523 & 10,04 & 9,81 & \\
\hline \hline
\end{tabular}

Based on Table 1 showed that MPE contained xanthones including $\alpha$-mangostin, $\gamma$-mangostin, Gar-C, GarD. The highest xanthone in MPE was $\alpha$-mangostin and the lowest xanthone was Gar-C.

\subsection{ABTS-Reducing Activity of MPE}

ABTS reducing activity of MPE and xanthones were measured as a representative of antioxidant activity. The $\boldsymbol{I C}_{\mathbf{5 0}}$ is the concentration of MPE and xanthones to scavenge $50 \%$ of the ABTS+ free radical (Table 2.)

\subsection{Anti-aggregation Platelet Activity of MPE}

To determine the antiaggregation paltelet of MPE and the xanthones, in this study using various inducer include COL, ADP, EPN were used. The data was analyzed by using ANOVA and continued with Tukey HSD post hoc test which can be seen in Table 3 .

Based on quantitative analysis of HPLC on MPE using marker of xathones showed that MPE contained xanthones $\alpha$-mangostin was 105 ppm, $\gamma$-mangostin was 7.20 ppm, Gar-D was 3.50 ppm, and Gar-C was 9.92 ppm. This data was validated with previous study that phytochemical study reported that the mangostin peel is rich in xanthones with biological activities such as anti-inflammatory, anti-bacterial, anti-cancer, anti-thrombotic, and anti-platelet aggregation [24]. The ripe or later MPE contained higher contents of flavonoids and $\alpha$-mangostin xanthone [25]. MPE contain $\alpha$-mangostin that has antiperoxidative effect [26]. MPE isolation resulted 8-hydroxycudraxanthone G, mangostingone, cudraxanthone G, 8-deoxygartanin, garcimangosone B, Gar-D, garcinone E, gartanin, 1 -isomangostin, $\alpha$-mangostin, $\gamma$-mangostin, mangostinone, smeathxanthone A, and tovophyllin A [27]. Mangosteen peel contain high concentration of xanthones. $\alpha$ Mangostin (1,3,6-trihydroxy-7-methoxy-2,8-bis (3-methyl-2-butenyl)-9 H-xanthen-9-one), and $\gamma$-mangostin (1,3,6,7-tetrahydroxy-2,8-bis(3-methylbut-2-enyl)xanthen-9-one) are the main xanthones from MPE [28]. A xanthones extract from G. mangostana peel was prepared by crystallization of a toluene contained $81 \% \alpha$ mangostin and $16 \% \gamma$-mangostin as the main contituents MPE [29]. MPE comprised of $75 \%-85 \% \alpha$ mangostin and 5\%-15\% $\gamma$-mangostin [30], [31]. MPE contain abundant xanthones (especially $\alpha$-mangostin) [32], high yield of xanthones such as $\alpha$ - and $\gamma$-mangostin in the pericarp of G. mangostana [33]. 
Table 2. The $\boldsymbol{I}_{\mathbf{5 0}}$ of ABTS-Reducing Activity of MPE and Xanthones [ABTS-Reducing Activity (\%) Was Calculated, Six Level Concentration of Samples Include 5, 2.5, 1.25, 0.625, 0.313, $0.156 \mu \mathrm{g} / \mathrm{ml}$. Linear Equation, Coefficient of Regression $\left(R_{2}\right)$ of MPE and Xanthones Were Calculated]

\begin{tabular}{lcccc}
\hline \hline Samples & $\begin{array}{c}\text { The highest activity of ABTS } \\
\text { reducing activity (\%) at } 5 \\
\mu \mathrm{g} / \mathrm{ml} \text { sample }\end{array}$ & Linear rquation & $R_{2}$ & $\begin{array}{l}I C_{50} \\
(\mu \mathrm{g} / \mathrm{ml})\end{array}$ \\
\hline MPE & 17.71 & $Y=2.8845 X+14.0378$ & 0.9925 & 15.93 \\
$\alpha$-mangostin & 91.69 & $Y=18.849 X+5.7458$ & 0.9179 & 2.348 \\
$\gamma$-mangostin & 50.88 & $Y=10.423 X+3.4319$ & 0.9233 & 4.468 \\
Gar-C & 15.76 & $Y=2.2044 X+4.8445$ & 0.9945 & 20.48 \\
Gar-D & 25.42 & $Y=3.1977 X+9.9334$ & 0.9959 & 12.53 \\
\hline \hline
\end{tabular}

Table 3. Mean and Standard Deviation of Platelet Aggregation Using ADP, COLL, EPN Inducer (\%)

\begin{tabular}{|c|c|c|c|}
\hline \multirow[t]{2}{*}{ Samples } & \multicolumn{3}{|c|}{ Inducer } \\
\hline & COLL $(10 \mu \mathrm{g} / \mathrm{ml})$ & ADP $(20 \mu \mathrm{M})$ & EPN $(300 \mu \mathrm{M})$ \\
\hline Control (Hyperaggregation individu) & $95.30 \pm 6.00 \mathrm{~d} A$ & $96.80 \pm 3.00$ e $\mathrm{A}$ & $95.80 \pm 3.60^{\mathrm{d}} \mathrm{A}$ \\
\hline DMSO & $88.00 \pm 7.00^{\mathrm{cd}} \mathrm{B}$ & $89.33 \pm 2.42$ de $B$ & $82.70 \pm 0.90 \mathrm{~cd} A$ \\
\hline MPE $(100 \mu \mathrm{g} / \mathrm{ml})$ & $91.00 \pm 1.41 \mathrm{~cd} B$ & $86.73 \pm 1.97$ cde $B$ & $20.03 \pm 2.43$ ab $\mathrm{A}$ \\
\hline MPE $(50 \mu \mathrm{g} / \mathrm{ml})$ & $95.23 \pm 1.16^{\mathrm{d}} \mathrm{A}$ & $96.17 \pm 0.75$ e $\mathrm{A}$ & $95.90 \pm 0.95 \mathrm{~d} A$ \\
\hline$\alpha$-mangostin $100 \mu \mathrm{g} / \mathrm{ml}$ & $86.60 \pm 5.52 \mathrm{~cd} B$ & $82.03 \pm 5.34 \mathrm{~cd} \mathrm{~B}$ & $18.93 \pm 4.54$ a $\mathrm{A}$ \\
\hline$\alpha$-mangostin $50 \mu \mathrm{g} / \mathrm{ml}$ & $89.40 \pm 2.46$ cd B & $83.57 \pm 6.76^{\mathrm{cd} B}$ & $30.27 \pm 7.04$ ab $\mathrm{A}$ \\
\hline$\gamma$-mangostin $100 \mu \mathrm{g} / \mathrm{ml}$ & $85.33 \pm 6.77$ cd B & $63.03 \pm 8.60^{\text {b } B}$ & $22.77 \pm 1.63$ ab $A$ \\
\hline$\gamma$-mangostin $50 \mu \mathrm{g} / \mathrm{ml}$ & $88.53 \pm 2.58$ cd $C$ & $39.90 \pm 1.44$ a $\mathrm{B}$ & $25.50 \pm 5.51$ ab $\mathrm{A}$ \\
\hline Garcinone-C $100 \mu \mathrm{g} / \mathrm{ml}$ & $80.30 \pm 1.10^{\text {с }} \mathrm{AB}$ & $83.90 \pm 1.20 \mathrm{~cd} B$ & $78.40 \pm 3.20$ с $\mathrm{A}$ \\
\hline Garcinone-C $50 \mu \mathrm{g} / \mathrm{ml}$ & $88.27 \pm 1.70 \mathrm{~cd} B$ & $88.27 \pm 4.82$ de $B$ & $18.57 \pm 4,73$ a $\mathrm{A}$ \\
\hline Garcinone-D $100 \mu \mathrm{g} / \mathrm{ml}$ & $84.50 \pm 4.00 \mathrm{~cd} A$ & $92.10 \pm 2.00$ de $\mathrm{B}$ & $86.53 \pm 2.30 \mathrm{~cd} A B$ \\
\hline Garcinone-D $50 \mu \mathrm{g} / \mathrm{ml}$ & $87.83 \pm 0.45 \mathrm{~cd} A$ & $89.23 \pm 4.37$ de $\mathrm{A}$ & $89.90 \pm 0.87 \mathrm{~cd} A$ \\
\hline Aspirin $100 \mu \mathrm{g} / \mathrm{ml}$ & $21.87 \pm 7.05$ а $\mathrm{AB}$ & $34.17 \pm 1.42$ a $\mathrm{B}$ & $17.07 \pm 5.85$ а $\mathrm{A}$ \\
\hline Aspirin $50 \mu \mathrm{g} / \mathrm{ml}$ & $45.37 \pm 1.90$ b $B$ & $75.80 \pm 1.61{ }^{\circ} \mathrm{C}$ & $35.60 \pm 5.27$ b A \\
\hline
\end{tabular}

The data showed mean \pm standard deviation. The different small letters at the same column (among antiplatlet agents) and capital letters at the same row (among inducers) show significant at the 5\% (Tukey HSD Post Hoc test).

Based on the Table 2, it showed that MPE and xanthones exhibited high antioxidant activity. This data was validated with previous study that MPE is rich in bioactive compounds including xanthones, which have been classified as very good antioxidants from several experimental results [34]. The strongest antioxdant were $\alpha$-mangostin and $\gamma$-mangostin was the main constituents of MPE. This data was consistent with previous study that $\alpha$-mangostin and $\gamma$-mangostin were the most active of antioxidant using peroxynitritescavenging bioassay compared to the others xanthone [27]. Aqueous extract of mangosteen peel had high antioxidant activity by using 1,1-diphenyl-2-picryl-hydrazyl (DPPH) free radical scavenging at $25 \mu \mathrm{g} / \mathrm{ml}$ was 92.57\% [14]. Gar-C had high DPPH free radical scavening with $\boldsymbol{I}_{\mathbf{5 0}}(3.039 \pm 0.102) \mu \mathrm{g} / \mathrm{ml}$ and Gar-D (143.386 \pm 10.064$) \mu \mathrm{g} / \mathrm{ml}[35]$.

Based on Table 3, it showed that $\alpha$-mangostin and $\gamma$-mangostin decreased the EPN-induced platelet aggregation compared with control (hyperaggretation individual) at all level concentration, $\alpha$-mangostin and $\gamma$-mangostin had high anti-aggregation activity on EPN inducer were comparable with aspirin as positive control, but not active on COLL and ADP inducer. MPE high dose had anti-aggregation activity on EPN inducer and Gar-C had anti-aggregation activity. This data was validated with previous research that omega-aminoalkoxylxanthones as xanthone derivatives was tested in vitro for their ability to inhibit platelet aggregation and cause vasorelaxing action, exhbited that some derivated compounds showed high antiaggregation toward thrombin-, arachidonic acid (AA)-, COLL-, and platelet activating factor (PAF)induced rabbit platelet aggregation and exhibited inhibition of primary and secondary aggregation induced by ADP in PRP [36]. Five from aminoalkanolic derivatives of xanthone inhibited thrombin-induced platelet aggregation, the most active compound was R-(+)-2-N-(7-chloro-2-xanthonemethyl)-2-N-methylamino-1- 
butanol at $40 \mu \mathrm{g} / \mathrm{ml}$ [37]. The extracts of bark of Yucca schidigera, seeds of grape and berries of Aronia melanocarpa (chokeberry) $(5-50 \mu \mathrm{g} / \mathrm{ml})$ rich in polyphenols exhibited as anti-aggregation platelet and reduced generation of $\mathrm{O}_{2}{ }^{-*}$ in blood platelets [38]. Wine polyphenol resveratrol (10-1000 $\left.\mu \mathrm{M}\right)$ inhibited platelet aggregation in healthy subjects induced by COLL $(5 \mu / \mathrm{ml})$, thrombin $(0.33 \mathrm{U} / \mathrm{ml})$, and ADP $(4 \mu \mathrm{M})$ [39] By my research exhibited that phenols and flavonoids showed commonly high antioxidant and antiaggregation platelet activities [22], [23].

Three factors are triggers platelet aggregation (agonist) that is a soluble plasma protein (fibrinogen) and platelet membrane-bound receptors (integrin $\alpha \operatorname{IIb} \beta 3$ atau GPIIb-III) that will trigger a simple platelet aggregation [40]. ADP P2Y1 and P2Y12 receptors can trigger a change in the shape pletelet aggregation of platelets (P2Y1), while aggregation (P2Y1), irreversible aggregation (P2Y12), the expression of P-selectin (P2Y12), the release of thromboxane $\mathrm{A} 2$ (P2Y1 and P2Y12) induction of procoagulant and aggregation ( P2Y12) [41]. Epinephrine to help $\alpha 2$ a receptor P2Y12 receptor mechanisms [41]. Collagen as an agonist to the receptor GPIIb will release ADP and thromboxane A2, GPIA/Iia platelet deployment, GPIV will trigger platelet aggregation, induce procoagulant activity through the release of $\mathrm{Ca}^{2+}[39,41]$. Aspirin is used for comparison because it has the ability anti-aggregation thromboxane A2 production through inhibition (TXA2) and inhibition of the enzyme cyclooxygenase [22]-[27].

The data (Table 3) showed that $\alpha$-mangosteen, $\gamma$-mangosteen had antiaggregation platelet induced by EPN, probably due to antioxidant activities (Table 3). Thromboxane production was induced by various agonists mediated by Reactive Oxygen Species (ROS) production and ROS production mediated by COX as well as other enzymes such as platelet isoforms of NADPH oxidase, xanthine oxidase, mitochondrial respiration [42], [43], and antioxidant inhibit the enzymes responsible for platelet ROS formation [22], [43], either by inhibiting the formation of endogenous mediators derived from phospholipid peroxidation, by blocking enzymatic free radical production, or by reducing platelet sensitivity to agonists by preventing lipid peroxidation [44].

\section{Conclusions}

MPE contain xathones including $\alpha$-mangostin, $\gamma$-mangostin, Gar-C, Gar-D. MPE and xanthones have high ABTS-reducing activity. MPE, $\alpha$-mangostin, $\gamma$-mangostin, Gar-D decrease EPN-induced aggregation platelet. $\alpha$-mangostin, $\gamma$-mangostin were the most active as antiaggregation and antioxidant activities.

\section{Acknowledgment}

We are grateful to the Directorate General for Higher Education, Ministry of National Education of Republic Indonesia, for Research Grant of Hibah Bersaing (2012) for financial support and thankful to Biomolecular and Biomedical Research Center, Aretha Medika Utama Bandung for technical and facilities support.

\section{References}

[1] WHO 2010. World heart day 2010. From http://www.who.int/cardiovascular_diseases/en/

[2] Widowati, W. (2007). The role of antioxidants as agents hipocholesterolemia, prevention of lipid oxidation and atherosclerosis. Damien Med. Magazine, 3(6), 227-234.

[3] Hoffbrand, A. V., \& Pettit, J. E. (1996). Essential Haematology. 2nd ed. Jakarta: Indonesia EGC.

[4] Gawaz, H. (2004). Role of platelets in coronary thrombosis and reperfusion of ischemic myocardium. Cardio Res., 54, 498-511.

[5] Hansson, G. K. (2005). Inflammation, atherosclerosis and coronary artery disease. N. Engl. J. Med., 352 (16), 1685-1695. 
[6] Michelson, A. D. (2004). Platelet function testing in cardiovascular diseases. Circulation, 110, 489-493.

[7] Krasopoulos, G., Brister, S. J., Beattie, W. S., \& Buchanan M. R. (2008). Aspirin "resistance" and risk of cardiovascular morbidity: systematic review and meta-analysis. British Medical Journal, 336, 195.

[8] Koshy, A. S., Anila, L., \& Vijayalaksmi, N. R. (2001). Flavonoids from garcinia combagia lower lipid levels in hypercholesterlemic rats. Food Chem., 72, 289-294.

[9] Ryszawa, N., Kawczyñska-Drózdz, A., Pryjma, J., Czesnikiewicz-Guzik, M., Adamek-Guzik, T., Naruszewicz, M., et al. (2006). Effects of novel plant antioxidants on platelet superoxide production and aggregation in atherosclerosis. J. Physiol. Pharmacol., 57(4), 611-626.

[10] Suksamrarn S., Suwannapoch, N., Phakhodee, W., Thanuhiranlert, J., Ratananukul, P., Chomnoi, N., et al. (2003). Antymicrobial activity of prenilated xanthon from the fruits of Garcinia mangostana. Chem. Pharm. Bull., 51(7), 857-859.

[11] Suksamrarn, S., Suwannapoch, N., Ratananukul, P., Aroonlerk, N., \& Suksamrarn, A. (2002). Xanthones from the green fruit hulls of Garcinia mangostana. J. Nat. Prod., 65, 761-763.

[12] Pedraza-Chaverri, J., Cárdenas-Rodríguez, N., Orozco-Ibarra, M., \& Pérez-Rojas, J. M. (2008). Medicinal properties of mangosteen (Garcinia mangostana). Food Chem. Toxicol., 46, 3227-3239.

[13] Widowati, W., Wijaya, L., Wragasetia, T. L., Bachtiar, I., Yelliantty, Y., \& Laksmitawati, D. R. (2013). Antioxidant, anticancer, and apoptosis-inducing effects of Piper extracts in HeLa cells. J. Exp. Integr. Med., 3(3), 225-230.

[14] Widowati, W., Rusmana, D., Hardiman, H., Tiono, H., Wargasetia, T. L., Pujimulyani, D., \& Yelliantty, Y. (2013). Mangosteen peel (Garcinia mangostana L.) extract for effervescent tablet. World Academy of Science. Proceedings of International Conference on Agricultural, Biotechnology, Biological and Biosystems Engineering (pp. 190-195). France: Paris.

[15] Ahmad, N. S., Ghani, M. N. A., Ali, A. M., Johari, S. A. T. T., \& Harun, M. H. (2012). High Performance Liquid Chromatography (HPLC) Profiling Analysis and Bioactivity of Baeckea frutescens L. (Myrtaceae). J. Plant Studies, 1(2), 101-108.

[16] Naganami, V., Rani, A. S., Satyakala, M., \& Reddy, G. N. V. C. (2013). High performance liquid chromatography (HPLC) analysis of embelin in different samples of Embelis ribes Burm. f.- a threatened medicinal plant of India. J. Med. Plants Res., 7(24), 1761-1767.

[17] Jang, A., Liu, X. D., Shin, M. H, Lee, B. D., Lee, S-K, Lee, J. H., \& Jo, C. (2008). Antioxidative potential of raw breast meat from broiler chicks fed a dietary medicinal herb extract mix. Poultry Sci., 87, 2382-2389.

[18] Thring, T. S. A., Hili, P., \& Naughton, D. P. (2009). Anti-collagenase, anti-elastase and anti-oxidant activities of extracts from 21 plants. BMC Complement Alternat. Med., 9(27), 1-11.

[19] Etoundi, C. B., Kuaté, D., Ngondi, J. L., \& Oben, J. (2010). Anti-amylase, anti-lipase and antioxidant effects of aqueous extracts of some Cameroonian spices. J. Nat. Prod., 3, 165-171.

[20] Chun-Han, L., Wen-Lian, S., Feng-Nien, K., \& Che-Ming, T. (1993). Antiplatelet activity of some prenyflavonoids. Biochem. Pharmacol., 45, 509-512.

[21] Helena Laboratories (2012). Helena Platelet Aggregation Reagents. USA: Beaumont' Texas 77704.

[22] Widowati, W., Ratnawati, H., Rusdi, U. D., Winarno, W., \& Immanuel, V. (2010). Phytochemicalassay and antiplatelet activity of fractions of velvet bean seeds (Mucuna pruriens L.). Hayati J. Biosci., 17(2), 85-90.

[23] Widowati, W., Herlina, T., Ratnawati, H., Mozef, T., \& Reisdian C. (2011). Antioxidant and platelet aggregation inhibitor activities of black tea (Camellia sinensis L.) extract and fractions. Medicinal Plants, $3(1), 21-26$.

[24] Akao, Y., Nakagawa, Y., Iunuma, M., \& Nozawa. Y. (2008). Anti-cancer effect of xanthones from pericarps of mangostin. Int. J. Mol. Sci., 9(3), 355-370.

[25] Pothitiratrat, W., Chomnawang, M. T., Supabphof, R., \& Gritsanapan, W. (2009). Comparison of bioactive 
compounds content, free radical scavenging and anti-acne inducing bacteria activities of extracts from the mangosteen fruit rind at two stages of maturity. Fitoterapia., 80(7), 442-447.

[26] Márquez-Valadez, B., Lugo-Huitrón, R., Valdivia-Cerda, V., Miranda-Ramírez, L. R., Pérez-De La Cruz, V., González-Cuahutencos, O., et al. (2009). The natural xanthone alpha-mangostin reduces oxidative damage in rat brain tissue. Nutr. Neurosci., 12(1), 35-42.

[27] Jung, H. A., Su, B. N., Keller, W. J., Mehta, R. G., \& Kinghorn, A. D. (2006). Antioxidant Xanthones from the Pericarp of Garcinia mangostana (Mangosteen). J. Agric. Food Chem., 54, 2077-2082.

[28] Matsumoto, K., Akao, Y., Yi, H., Ohguchi, K., Ito, T., Tanaka, T. et al. (2004). Preferential target is mitochondria in alpha-mangostininduced apoptosis in human leukemia HL60 cells. Bioorg. Med.Chem., 12(22), 5799-5806.

[29] Aisha, A. F. A., Abu-Salah, K. M., Ismail, Z., \& Majid, A. M. S. A. (2012). In vitro and in vivo anti-colon cancer effects of Garcinia mangostana xanthones extract. BMC Complement Alternat. Med., 12(04), 1-10.

[30] Nabandith, V., Suzui, M., Morioka, T., Kaneshiro, T., Kinjo, T., Matsumoto, K., et al. (2004). Inhibitory effects of crude alpha-mangostin, a xanthone derivative, on two different categories of colon preneoplastic lesions induced by 1, 2-dimethylhydrazine in the rat. Asian Pac. J. Cancer Prev., 5(4), 433438.

[31] Shibata, M. A., Matoba, Y., Tosa, H., \& Iinuma. M. (2013). Effects of mangosteen pericarp extracts against mammary cancer. Altern. Integ. Med., 2(8), 1-5.

[32] Yodhnu, S., Sirikatitham, A., \& Wattanapiromsakul, C. (2009). Validation of lc for the determination of $\alpha-$ mangostin in mangosteen peel extract: a tool for quality assessment of Garcinia mangostana L. J. Chromatogr. Sci., 47(3), 185-189.

[33] Balunas, M. J., Su, B., Brueggemeier, R. W., \& Kinghorn, A. D. (2008). Xanthones from the botanical dietary supplement mangosteen (Garcinia mangostana) with aromatase inhibitory activity. J. Nat. Prod., 71(7), 1161-1166.

[34] Martinez, A., Hernández-Marin, E., \& Galano, A. (2012). Xanthones as antioxidants: A theoretical study on the thermodynamics and kinetics of the single electron transfer mechanism. Food Funct., 3(4), 442450.

[35] Tjahjani, S., \& Widowati, W. (2013). The Potency of xanthones as antioxidant and antimalarial, and their synergism with artemisinin in vitro. J. Indon. Med. Assoc., 6(3), 95-99.

[36] Lin, K. W., Fang, S. C., Hung, C. F., Shieh, B. J., Yang, S. C., Teng, C. M., \& Lin, C. N. (2009). Synthesis, antiplatelet and vasorelaxing activities of xanthone derivatives. Arch. Pharm. (Weinheim), 342(1), 19-26.

[37] Rajtar, G., Zolkowska, D., Kleinrok, Z., \& Marona, H. (1999). Antiplatelets activity of some xanthone derivatives. Acta Poloniae Pharmaceutica-Drug Res., 56(4), 319-324.

[38] Olas, B., Wachowicz, B., Tomczak, A., Erler, J., Stochmal, A., \& Oleszek, W. (2008). Comparative antiplatelet and antioxidant properties of polyphenol-rich extracts from: berries of Aronia melanocarpa, seeds of grape and bark of Yucca schidigera in vitro. Platelets, 19(1), 70-77.

[39] Wang, Z., Huang, Y., Zou, J., Cao, K., Xu, Y., \& Wu, J. M. (2002). Effects of red wine and wine polyphenol resveratrol on platelet aggregation in vivo and in vitro. Int. J. Mol. Med., 19(1), 77-79.

[40] Jackson. S. P. (2007). The growing complexity of platelet aggregation. Blood, 109(12), 5087-5095.

[41] Jennings, L. K. (2009). Mechanisms of platelet activation: Need for new strategies to protect against platelet-mediated atherothrombosis. Thromb. Haemost., 102(2), 248-257.

[42] Chang, M. C., Uang, B. J., Wu, H. L., Lee, J. J., Hahn, H. N., \& Jeng, J. H. (2002). Inducing the cell cycle arrest and apoptosis of oral KB carcinoma cells by hydroxychavicol: roles of glutathione and reactive oxygen species. Br. J. Pharmacol., 135, 619-630.

[43] Iuliano, L., Violi, F., Pedersen, J. Z., Pratico, D., Rotilio, G., \& Balsano, F. (1992). Free radical-mediated 
platelet activation by hemoglobin released from red blood cells. Arch. Biochem. Biophys., 299, 220-224. [44] Murphy, K. J., Chronopoulos, A. K., Singh, I., Francis M. A., Moriarty, H., Pike, M. J., et al. (2002). Dietary flavanols and procyanidin oligomers from cocoa (Theobroma cacao) inhibit platelet function. Am. J. Clin. Nutr., 77(6), 1466-1473.

Wahyu Widowati was born on April 17, 1960 in Malang. She is working in the Faculty of Medicine, Maranatha Christian University, Jl. Prof. Drg. Suria Sumantri 65 Bandung 40164. She did the undergraduate program from Brawijaya University-Malang, Indonesia from 1979-1984. And now she got the doctoral program in Brawijaya University-Malang, Indonesia. Her research interests include pharmacology, biomolecular, stem cell and cell culture. 